\title{
Validation and Optimization of a Simple RP-HPLC Method for the Determination of Paracetamol in Human Serum and its Application in a Pharmacokinetic Study with Healthy Bangladeshi Male Volunteers
}

\author{
Anisa Alam Tanam¹, Mohammad Firoz Khan ${ }^{1}$, Ridwan Bin Rashid², Md. Zakir \\ Sultan ${ }^{3}$ and Mohammad A. Rashid ${ }^{4}$
}

${ }^{1}$ Department of Pharmacy, State University of Bangladesh, Dhaka-1205, Bangladesh

${ }^{2}$ Department of Microbiology, University of Dhaka, Dhaka-1000, Bangladesh

${ }^{3}$ Centre for Advanced Research in Sciences, University of Dhaka, Dhaka-1000, Bangladesh

${ }^{4}$ Department of Pharmaceutical Chemistry, Faculty of Pharmacy, University of Dhaka,

Dhaka-1000, Bangladesh

Received: June 23, 2014; Accepted: July 01, 2014; Published (web): July 06, 2014

\begin{abstract}
Acetaminophen (paracetamol) is an analgesic and antipyretic agent with minimum anti-inflammatory properties. In the present study a simple, fast, accurate, precise and reproducible RP-HPLC method has been developed and validated for the quantification of paracetamol in human serum samples using theophylline as internal standard. Protein precipitation with perchloric acid was employed in the extraction of paracetamol and theophylline from biological matrix. The chromatographic separation was accomplished on Phenomenex $\mathrm{C}_{18}$ column with a mobile phase comprising of $0.05 \mathrm{mM}$ sodium sulfate buffer (pH $2.2 \pm 0.02$ adjusted with phosphoric acid) and acetonitrile at a ratio of $93: 7$ at a flow rate of $1.0 \mathrm{ml} / \mathrm{min}$. The chromatogram was monitored by UV detection at a wavelength of $254 \mathrm{~nm}$. The method was validated over a linear concentration range of 2-100 $\mu \mathrm{g} / \mathrm{ml}$ and limit of quantification (LOQ) was $1.61 \mu \mathrm{g} / \mathrm{ml}$ with a correlation coefficient $\left(\mathrm{r}^{2}\right) 0.997$. The intra-day and inter-day precision expressed as relative standard deviation were found to be $0.49-2.68 \%$ and $0.36-3.44 \%$, respectively. The average recovery of paracetamol from serum ranged from $99.0-106.4 \%$. The method was successfully applied to a pharmacokinetic study after oral administration of immediate release paracetamol tablet $(1000 \mathrm{mg})$ in four healthy Bangladeshi volunteers. The mean $C_{\max }$ was found to be $11.03 \pm 3.21 \mu \mathrm{g} / \mathrm{ml}$, which occurred at $\mathrm{T}_{\max }$ of $0.88 \pm 0.14 \mathrm{hr}$. The half life, $\mathrm{AUC}_{0-8}$ and $\mathrm{AUC}_{0-\infty}$ values were found to be $3.09 \pm 0.71 \mathrm{hr}, 31.06 \pm 6.57 \mathrm{hr}-\mu \mathrm{g} / \mathrm{ml}$ and $37.92 \pm 9.51 \mathrm{hr}-$ $\mu \mathrm{g} / \mathrm{ml}$, respectively.
\end{abstract}

Key words: Paracetamol, method development, validation, pharmacokinetics, Bangladeshi volunteer

\section{INTRODUCTION}

Paracetamol [acetaminophen, N-(4hydroxyphenyl) acetamide] (Figure 1) is a widely used analgesic and antipyretic agent singly or in combination with other drugs including caffeine. ${ }^{1}$ Acetaminophen is a synthetic, nonopiate, centrally acting analgesic-antipyretic drug derived from 4aminophenol. ${ }^{2}$ Oral acetaminophen is rapidly and almost completely absorbed from the gastrointestinal tract primarily in the small intestine, with negligible

Correspondence to: Mohammad A. Rashid Tel.: +88-02-9661900-73, Extn.- 8132; Fax: +88-02-9667222; E-mail: rashidma@du.ac.bd

Dhaka Univ. J. Pharm. Sci. 13(2): 125-131, 2014 (December) absorption occurring in the stomach. ${ }^{3,4}$ This absorption process occurs by passive nonionic diffusion. ${ }^{5}$ After absorption the acetaminophen is primarily eliminated from the body through the formation of glucuronide and sulfate conjugates. ${ }^{6}$

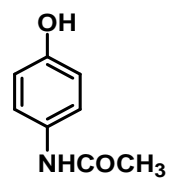

$1 \mathrm{~A}$

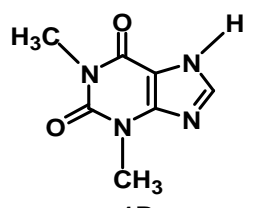

$1 \mathrm{~B}$
Figure 1. Chemical structures of paracetamol $(1 \mathrm{~A})$ and theophyline (1B).

The present study was conducted to optimize and validate an analytical method for the determination of 
paracetamol in human plasma so that we can conduct a pharmacokinetic study of paracetamol in Bangladeshi male volunteers using this method. This study of paracetamol will provide some pharmacokinetic parameters like elimination half life $\left(\mathrm{t}_{1 / 2}\right)$ and rate constant $\left(\mathrm{k}_{\mathrm{el}}\right), \mathrm{T}_{\max }$ and $\mathrm{C}_{\max }$ etc, which are essential for designing an effective dosage regimen. $^{7}$

\section{MATERIALS AND METHODS}

Drugs and reagents. Paracetamol, theophylline (internal standard) (Figure 1) and paracetamol tablets were kind gift of Beximco Pharmaceuticals Ltd., Bangladesh. HPLC grade acetonitrile was obtained from Fisher Scientific Company, UK. Sodium sulfate, phosphoric acid and other reagents were of analytical grade and used without further purification. A Milli-Q ${ }^{\circledR}$ (Millipore, France) water purification system was used to obtain purified water for the HPLC analysis.

Instrumentation. High performance liquid chromatographic system (Shimadzu-UFLC Prominence) (Model- SCL 10Avp) equipped with a manual injector containing a $20 \mu \mathrm{l}$ loop and UVVisible detector (Model-SPD 10Avp) was used for the analysis. The data was recorded using LCsolutions software (Version 1.03 SP3, Shimadzu Corporation, Kyoto, Japan). Phenomenex $\mathrm{C}_{18}$ (4.6 $\mathrm{mm} \times 250 \mathrm{~mm} ; 10 \mu \mathrm{m})$ analytical column was used for the analysis.

\section{Collection of serum samples}

(a) Volunteers: Four healthy male Bangladeshi volunteers were enrolled in this study with average age $20.50 \pm 0.53$ years (range $20-21$ years); average body weight $69.13 \pm 7.61 \mathrm{~kg}$ (range $62-85 \mathrm{~kg}$ ); average height $1.71 \pm 0.07 \mathrm{~m}$ (range $1.60-1.80 \mathrm{~m}$ ) and average body mass index (BMI) $23.50 \pm 1.44$ $\mathrm{kg} / \mathrm{m}^{2}$ (range $21.60-26.23 \mathrm{~kg} / \mathrm{m}^{2}$ ). All the volunteers completed the study without any adverse effect.

(b) Inclusion and exclusion criteria: All volunteers were examined to verify their health status. The examinations included medical history, vital sign measurements, electrocardiography (ECG), blood sample analysis (basic profile, complete blood cell count, bleeding time, clotting time, prothrombin time, viral serology), and urine analysis (sediment, drugs). Volunteers with relevant clinical, analytical, or ECG abnormalities were excluded from the trial. Additional exclusion criteria were smoking, history of alcohol or other drug abuse, consumption of any medication within one month prior to study commencement, participation in a clinical trial in the 4 months before enrollment, history of clinically important illness or major surgery in the 6 months before enrollment, inability to relate to and/or cooperate with the investigators; medication, allergy, illnesses or disorders that could affect the absorption, distribution, metabolism, and/or excretion of drugs, blood loss or donation in the 3 months before enrollment; blood or blood-derivative transfusion in the 6 months before enrollment; and exhausting physical exercise in the 72 hours before enrollment. All eligible volunteers provided written informed consent to participate and were free to withdraw from the study at any time without any obligation.

(c) Study design: The study was conducted in the Department of Pharmacy, State University of Bangladesh in association with a well-equipped private hospital in Dhaka, Bangladesh in accordance with the International Conference of Harmonization (ICH) guidelines for Good Clinical Practice (GCP) and in compliance with the Declaration of Helsinki and its amendments. ${ }^{8-11}$ The study was a single-dose, randomized, open-label, one-period study. A single dose of $1000 \mathrm{mg}$ of paracetamol tablet formulation was administered with $250 \mathrm{~mL}$ of water after an overnight fasting. A standardized breakfast and lunch were given at 4 and 8 hours after drug administration, respectively. During the study period, the volunteers were under medical surveillance to report any adverse events.

(d) Blood sampling: The blood of the volunteers was collected with the help of sterile disposable syringe. $2 \mathrm{~mL}$ of blood was drawn in each time of collection. Blood samples were collected prior to dosing $(0 \mathrm{~h})$ and at $0.25,0.5,0.75,1.0,1.5,2.0,3.0$, 5.0 and $8.0 \mathrm{~h}$ after dosing. The blood samples were then centrifuged at $4000 \mathrm{rpm}$ for 15 minutes at room 
temperature to separate serum and stored at $-80^{\circ} \mathrm{C}$ until assayed for paracetamol content.

Chromatographic conditions. All analyses of paracetamol in serum were done according to the method described by Brunner and Bai after slight modification followed by validation. ${ }^{12}$ Mobile phase consisting of a mixture of sodium sulfate buffer $(0.05$ $\mathrm{mM}$ sodium sulfate, $\mathrm{pH} 2.2 \pm 0.02$ adjusted with phosphoric acid) and acetonitrile in the ratio of 93:7 $(\mathrm{v} / \mathrm{v})$ was delivered at a flow rate of $1.0 \mathrm{ml} / \mathrm{min}$ with UV detection at $254 \mathrm{~nm}$. The injection volume was $20 \mu \mathrm{L}$ for standard and samples. The mobile phase was filtered through a $0.22 \mu \mathrm{m}$ membrane filter, sonicated and degassed before use. Analysis was performed at room temperature $\left(\sim 25^{\circ} \mathrm{C}\right)$ temperature and the total run time was $15 \mathrm{~min}$.

Preparation of internal standard. Paracetamol stock solution was prepared by dissolving appropriate amount of powdered paracetamol in mobile phase (buffer- acetonitrile $=93: 7$ ) to have a concentration of $100 \mu \mathrm{g} / \mathrm{ml}$. Similarly a stock solution of theophylline (internal standard) was prepared in $6 \%$ perchloric acid having a concentration of $100 \mu \mathrm{g} / \mathrm{mL}$. Calibration standards were obtained by adding required amount of paracetamol stock solution to 80 $\mu \mathrm{L}$ of drug free serum. These samples were vortexed for 15 seconds and then $160 \mu \mathrm{l}$ of theophylline solution $(100 \mu \mathrm{g} / \mathrm{mL})$ was added to it. The mixtures were again vortexed for 30 seconds and finally centrifuged at 4,000 rpm for 15 minutes. The clear supernatants were removed and kept in glass vials. A $20 \mu \mathrm{L}$ aliquot was injected into the HPLC system for analysis.

Sample preparation. To $80 \mu \mathrm{l}$ of serum sample, $160 \mu \mathrm{L}$ of theophylline $(100 \mu \mathrm{g} / \mathrm{ml}$ solution) was added and vortexed for 1 minute. Then it was centrifuged for 15 minutes and the supernatant was collected in eppendorf tubes and stored at $-80^{\circ} \mathrm{C}$ until further analysis. Then $20 \mu \mathrm{l}$ of the supernatant was injected into the column for HPLC analysis.

Bioanalytical method validation. The experiments for bioanalytical method validation were carried out by following ICH and FDA guidelines. ${ }^{8-13}$ (a) Specificity: The specificity of the method was ascertained by comparing chromatograms of treated blank serum sample, calibrating sample spiked with paracetamol and internal standard, and processed serum sample of volunteer after oral administration of the drug spiked with internal standard.

(b) Linearity and range: Seven solutions having concentrations of $2,5,10,20,40,80$ and $100 \mu \mathrm{g} / \mathrm{mL}$ were prepared and analyzed by HPLC after three replicate injections. The average peak areas were plotted against respective concentration. The linearity of the proposed method was evaluated by using calibration curve to calculate coefficient of correlation and intercept values.

(c) Limit of detection ( $L O D)$ : LOD is a parameter that provides the lowest concentration of analyte in a sample that can be detected, but cannot be precisely quantified, under the stated experimental conditions. The LOD was estimated by the following equation:

$$
L O D=\frac{3.3 \times S D}{\sigma}
$$

Where, $\mathrm{SD}=$ standard deviation of response

$$
\sigma=\text { slope of regression line }
$$

(d) Limit of quantification (LOQ): The LOQ is the lowest concentration of analyte that can be determined with acceptable precision and accuracy under the stated experimental conditions. ${ }^{9,10}$ The LOQ was estimated by the following equation:

$$
L O Q=\frac{10 \times S D}{\sigma}
$$

Where, $\mathrm{SD}=$ standard deviation of response

$$
\sigma=\text { slope of regression line }
$$

(e) Precision: Precision of the assay was assessed with respect to both repeatability and reproducibility. The precision of an analytical method is the degree of agreement among individual test results where the method is applied repeatedly to multiple samplings. It was checked by intra- and inter-day repeatability of responses after five replicate injections and expressed as RSD \% amongst responses using the formula $[\mathrm{RSD}(\%)=($ Standard deviation/Mean) x $100 \%$ ]. In the current method development and validation protocol, precision was 
determined by analyzing single concentration of control samples. The RSD to be determined at each concentration level should not exceed $15 \%$ for the method to be precised. ${ }^{13,14}$

(f) Accuracy: The accuracy is a measure of the systematic error or bias and, is defined as the agreement between the measured concentration and nominal value. It is calculated as percentage of drug recovered. ${ }^{13,14}$ To evaluate the accuracy of the proposed method, successive analysis $(\mathrm{n}=3)$ for three different concentrations of standard paracetamol solutions were carried out by using the proposed method.

\section{Pharmacokinetic study}

Pharmacokinetics and statistical analysis. Pharmacokinetic properties of paracetamol were calculated by a non-compartmental approach from serum concentrations of paracetamol using software Kinetica (Version 5.0, Thermo Electron Corporation, UK). $C_{\max }$ was estimated directly from observed concentrations and $\mathrm{T}_{\max }$ as the corresponding time point at which $\mathrm{C}_{\max }$ occurred. $\mathrm{AUC}_{\mathrm{o}-\mathrm{t}}$ was calculated by the linear trapezoidal method until the last measurable serum drug concentration and $\mathrm{AUC}_{\mathrm{o}-\infty}$ was calculated as $\mathrm{AUC}_{\mathrm{o}-\infty}=\mathrm{AUC}_{\mathrm{o}-\mathrm{t}}+\mathrm{C}_{\mathrm{last}} / \mathrm{k}_{\mathrm{el}}$. Here, $\mathrm{k}_{\mathrm{el}}$ was the terminal elimination rate constant calculated by linear least square regression of the last three to four time points in the log concentration time profile. The terminal half life was calculated by the following equation: ${ }^{10}$

$$
t_{\frac{1}{2}}=\frac{0.693}{k_{e l}}
$$

\section{RESULTS AND DISCUSSION}

HPLC method is one of the most powerful analytical tools in clinical pharmacokinetics for its selectivity, sensitivity and reproducibility. ${ }^{13}$ The goal of this work was to conduct an in vivo pharmacokinetic study of paracetamol in Bangladeshi male volunteers. For this reason, a simple, rapid and sensitive assay method was developed and validated. Protein precipitation technique by centrifugation was utilized in the extraction of paracetamol and theophylline from the serum samples. Chromatographic conditions, especially the composition and nature of the mobile phase, were optimized through several trials to achieve the best resolution and increase the signal of paracetamol and theophylline. Using the optimized extraction method and chromatographic conditions, the HPLC method was evaluated in terms of specificity, linearity, limit of detection, limit of quantification, precision and accuracy. A good separation was achieved using buffer of sodium sulfate ( $\mathrm{pH} 2.2)$ and acetonitrile at a ratio of 93:7 (v/v) at a flow-rate of $1.0 \mathrm{ml} / \mathrm{min}$.

The specificity and selectivity of the method were assessed by comparing chromatograms of a blank serum (Figure 2A), serum spiked with paracetamol and internal standard (Figure 2B), treated volunteer's serum sample spiked with internal standard (Figure 2C). The retention times were 9.87 and $11.5 \mathrm{~min}$ for paracetamol and theophylline, respectively. As shown in the figures, there were no interfering peaks from endogenous substances at the elution time of paracetamol and theophylline. Therefore, the method exhibited good specificity and selectivity.

When average peak area $(y)$ was plotted against concentration range of $2-100 \mu \mathrm{g} / \mathrm{ml}$, a good correlation coefficient was obtained. For the equation of calibration curve, correlation coefficient $\left(\mathrm{r}^{2}\right)$ was obtained as 0.997 which was within the acceptable guidelines and it showed good linear relationship of the newly developed methods. The slope $(\mathrm{m})$ and intercept (c) of the calibration curve were found to be 30476 and 31528 (Figure 3).

The LOQ and LOD of paracetamol were found to be $1.61 \mu \mathrm{g} / \mathrm{ml}$ and $0.68 \mu \mathrm{g} / \mathrm{ml}$, respectively. The precision of the method has been shown in Table 1. The intra-day accuracy was found to be in the range of $98.5-99.7 \%$ while the inter-day accuracy was in the range of $99.1-103.0 \%$. The intra-day precision (\% RSD) was in the range of $0.49-2.68 \%$ and the inter-day precision was in the range of $0.36-3.44 \%$. Since all the values of accuracy and \% RSD were within the acceptable range, the results indicated that the method was reliable, reproducible and accurate. 

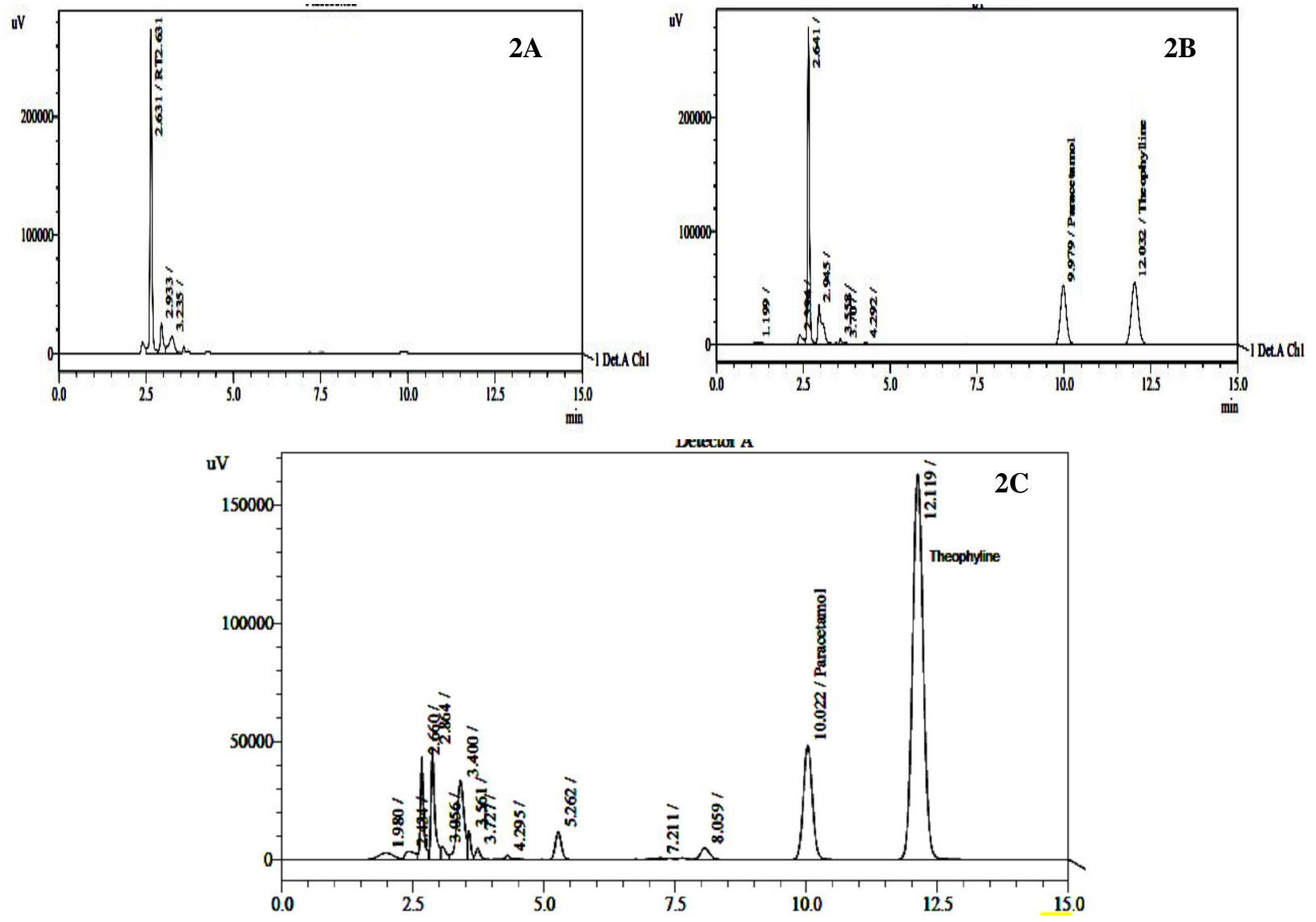

Figure 2. Chromatograms for specificity and selectivity. Blank serum (2A), serum spiked with paracetamol and internal standard (2B) and serum sample collected from a volunteer after oral administration of paracetamol (2C).

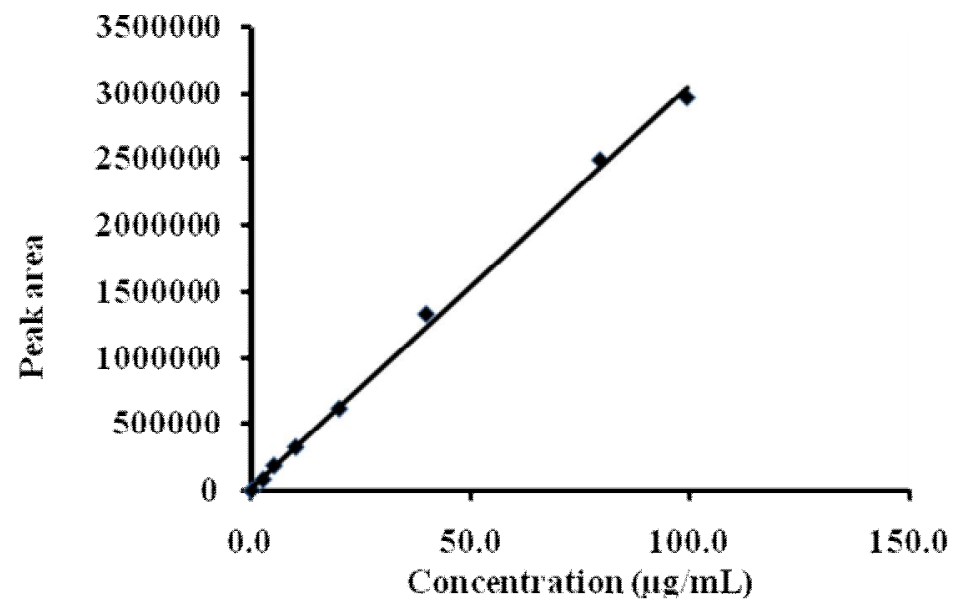

Figure 3. Standard calibration curve of paracetamol.

The recoveries of paracetamol were determined at five different concentrations $(10,15,20,25$ and 30 $\mu \mathrm{g} / \mathrm{mL}$ ) and are shown in Table 2. The method showed good efficiency in terms of recovery as the average recovery for paracetamol was $102.3 \%$. 
Table 1. Accuracy and precision of paracetamol in human serum.

\begin{tabular}{|c|c|c|c|c|}
\hline \multicolumn{5}{|c|}{ Accuracy and precision } \\
\hline \multirow{2}{*}{$\begin{array}{l}\text { Injected } \\
\text { conc. } \\
(\mu \mathrm{g} / \mathrm{ml})\end{array}$} & \multicolumn{2}{|c|}{ Intra-day $(n=3)$} & \multicolumn{2}{|c|}{ Inter-day $(n=3)(\%$ RSD $)$} \\
\hline & Accuracy & $\begin{array}{l}\text { Precision } \\
\text { (\% RSD) }\end{array}$ & Accuracy & $\begin{array}{l}\text { Precision } \\
\text { (\% RSD) }\end{array}$ \\
\hline 15 & $98.5 \%$ & $1.46 \%$ & $100.4 \%$ & $3.44 \%$ \\
\hline 30 & $99.7 \%$ & $2.68 \%$ & $103.0 \%$ & $1.57 \%$ \\
\hline 45 & $99.6 \%$ & $0.49 \%$ & $99.1 \%$ & $0.36 \%$ \\
\hline
\end{tabular}

Table 2. Paracetamol recovery from serum samples $(n=2)$.

\begin{tabular}{cccc}
\hline $\begin{array}{c}\text { Injected } \\
\text { conc. }(\mu \mathrm{g} / \mathrm{ml})\end{array}$ & $\begin{array}{c}\text { Recovered } \\
\text { conc. }(\mu \mathrm{g} / \mathrm{ml})\end{array}$ & $\begin{array}{c}\% \\
\text { Recovery }\end{array}$ & $\begin{array}{c}\text { Average } \\
\text { recovery }(\%)\end{array}$ \\
\hline 9.9 & 10.06 & 101.5 & \\
14.9 & 15.10 & 101.5 & \\
19.8 & 19.63 & 99.0 & 102.3 \\
24.8 & 26.36 & 106.4 & \\
29.7 & 30.65 & 103.0 & \\
\hline
\end{tabular}

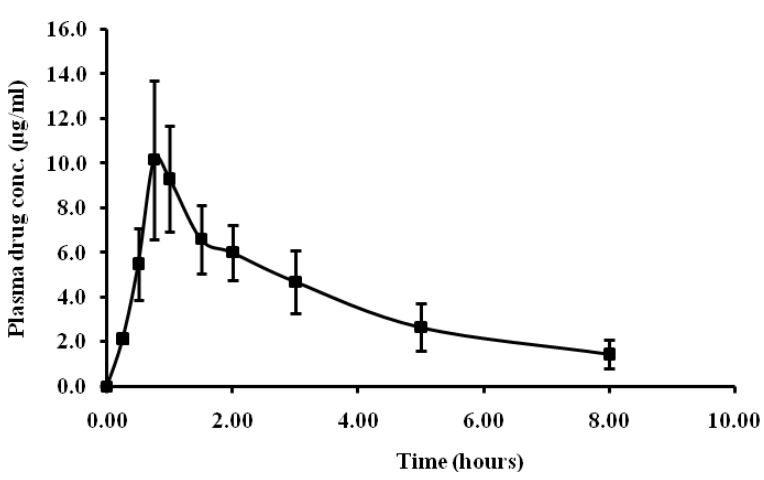

Figure 4. Mean (SD) paracetamol plasma drug concentration versus time cure over (AUC) 8 hours in adult healthy Bangladeshi volunteers $(\mathrm{N}=4)$.

Table 3. Pharmacokinetic parameter after administration of $1000 \mathrm{mg}$ single oral dose of paracetamol in healthy Bangladeshi male volunteers $(\mathrm{N}=4)$.

\begin{tabular}{lc}
\hline \multicolumn{1}{c}{ Parameters } & Mean $\pm \mathrm{SD}$ \\
\hline $\mathrm{C}_{\max }(\mu \mathrm{g} / \mathrm{ml})$ & $11.03 \pm 3.21$ \\
$\mathrm{~T}_{\max }(\mathrm{hr})$ & $0.88 \pm 0.14$ \\
$\mathrm{AUC}_{0-8}(\mathrm{hr} \mu \mathrm{g} / \mathrm{ml})$ & $31.06 \pm 6.57$ \\
$\mathrm{AUC}_{0-\infty}(\mathrm{hr} \mu \mathrm{g} / \mathrm{ml})$ & $37.92 \pm 9.51$ \\
$\mathrm{k}_{\mathrm{el}}\left(\mathrm{hr} r^{-1}\right)$ & $0.23 \pm 0.06$ \\
$\mathrm{t}_{1 / 2}(\mathrm{hr})$ & $3.09 \pm 0.71$ \\
$\mathrm{MRT}(\mathrm{hr})$ & $4.67 \pm 0.99$ \\
\hline
\end{tabular}

Pharmacokinetic properties of paracetamol.

The mean serum concentration-time profile of paracetamol is shown in Figure 4 and relevant pharmacokinetic parameters have been listed in Table 3. The mean $\mathrm{C}_{\max }$ was found to be $11.03 \pm 3.21 \mu \mathrm{g} / \mathrm{ml}$ occurring at $\mathrm{T}_{\max }$ of $0.88 \pm 0.14 \mathrm{hr}$. The half life,
$\mathrm{AUC}_{0-8}$ and $\mathrm{AUC}_{0-\infty}$ values were found to be $3.09 \pm$ $0.71 \mathrm{hr}, 31.06 \pm 6.57 \mathrm{hr}-\mu \mathrm{g} / \mathrm{ml}$ and $37.92 \pm 9.51 \mathrm{hr}-$ $\mu \mathrm{g} / \mathrm{ml}$, respectively. These data are in accordance with the previously reported values. ${ }^{3}$

\section{CONCLUSION}

The present method of HPLC method was simple, rapid, accurate, precise, reproducible and selective enough to allow the analysis of paracetamol in human serum. The extraction process used was also very easy and rapid. The method was successfully applied for the determination of pharmacokinetic parameters of paracetamol in healthy Bangladeshi male volunteers. For establishing pharmacokinetic parameters of paracetamol in Bangladeshi volunteers further studies are required since the number volunteers involved in the present study was low and only male volunteers were included. However, this modified and optimized method can be used to conduct bioequivalence study of paracetamol.

\section{REFERENCES}

1. Brune, K. 1988. The pharmacological profile of non-opioid (OTC) analgesics: aspirin, paracetamol (acetaminophen), ibuprofen, and phenazones. Agents Actions Suppl. 25, 9-19.

2. http://www.tylenolprofessional.com/assets/TYL_PPI.pdf. (Date of access: May 20, 2014).

3. Toes, M. J., Jones, A. L. and Prescott, L. 2005. Drug interactions with paracetamol. Am. J. Ther. 12, 56-66.

4. Grattan, T., Hickman, R., Darby-Dowman, A., Hayward, M., Boyce, M. and Warrington, S. 2000. A five way crossover human volunteer study to compare the pharmacokinetics of paracetamol following oral administration of two commercially available paracetamol tablets and three development tablets containing paracetamol in combination with sodium bicarbonate or calcium carbonate. Eur. J. Pharm. Biopharm. 49, 225-229.

5. Prescott, L. 2001. Paracetamol (acetaminophen): A critical bibliographic review. 2nd ed. New York, NY: Taylor \& Francis Inc.

6. Tarloff, J. B., Goldstein, R.S., Sozio, R.S., Hook, J.B. 1991. Proc. Soc. Exp. Biol. Med. 197, 297.

7. Ullah M.A., Azad, M.A.K., Sultana, R.; Kabir, E.R., Latif, A.H.M.M. and Hasnat, A. 2009. Pharmacokinetic study of amoxicillin capsule in healthy Bangladeshi subjects using urinary excretion data. Dhaka Univ. J. Pharm. Sci. 8, 53-59. 
8. European agency for the evaluation of medicinal products. 2002. International Conference on Harmonization World Health Organization. Available from: http://www.ema.europa.eu/pdfs/human/ich/013595en.pdf.Accessed December 20, 2010.

9. Akteruzzaman, M., Rahman, A., Sultan, M.Z., Islam, F., Salam M.A. and Rashid, M.A. 2012. Development and validation of a simple RP-HPLC method for simultaneous estimation of metformin hydrochloride and rosiglitazone in pharmaceutical dosage forms. Dhaka Univ. J. Pharm. Sci. 11, 157-163.

10. World Medical Association Declaration of Helsinki. 2008. Adopted by the $18^{\text {th }}$ WMA General Assembly, Helsinki, Finland, June 1964, and amended by the 59 $9^{\text {th }}$ WMA General Assembly. Available from: http://www.wma.net/en/30publications/10policies/b3/index.html. Accessed June 20, 2010.
11. Islam, M.M., Ullah, M.A., Iqbal, N., Maruf, A.A., Shohag, M.H., Harun, S., Akter, K.A., Begum, B., Latif, A.H.M.M., Hasnat, A. 2011. Relative bioavailability and pharmacokinetic study of two trimetazidine modified release formulations in healthy Bangladeshi male volunteers. Arzneimittelforschung -Drug Res. 61, 393-398.

12. Brunner L. J. and Bai S. 1999. Simple and rapid essay for acetaminophen and conjugated metabolites in low volume serum samples. Journal of Chromatography B. 732. 323-329.

13. U.S. food and drug administration. 2001. Guidance for industry: Bioanalytical method validation, Center for drug evaluation and research, Rockville, MD, pp. 1-22.

14. Shah, P.V., Midha, K.K., Findlay, W.A.J., Hill, M.H., Hulse, D.J., Mcgilveray, J.I., McKay, G., Miller, K.J., Patnaik, R,N., Powell, M.L., Tonelli, A., Viswanathan, C.T., Yacobi, A. 2000. Bioanalytical method validation - a revisit with a decade of progress. Pharm. Res. 17, 1551-1557. 